\title{
FREQUENCY OF ANTIBODIES IN HAEMOLYTIC DISEASE OF FOETUS AND NEWBORN
}

Sajith Vilambilin, Meena Dharmadas², Kumari Krishnakumariamma Chakrapani Usha ${ }^{3}$, Shaiji Panthiyil Shahulhameed ${ }^{4}$, Chitra James ${ }^{5}$, Anjaly Padmavilas Sasikala6, Soonam John ${ }^{7}$, Vineeth Rajagopal ${ }^{8}$

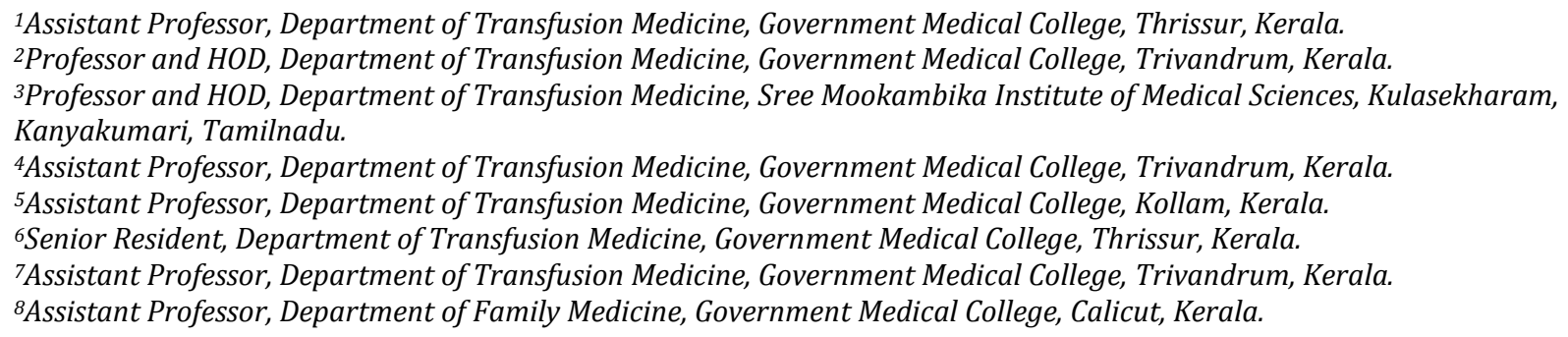

ABSTRACT

\section{BACKGROUND}

Haemolytic disease of foetus and newborn (HDFN) is triggered by enhanced destruction of red blood cell due to immune-mediated destruction, intrinsic abnormalities, acquired aberrations, etc. Lifespan of infant's erythrocytes are shortened by the action of placentally transferred maternal antibodies in immune-mediated HDFN.

The aim of this study was to identify the frequency of maternal antibodies in neonates with hyperbilirubinaemia.

Settings and Design- This was a cross-sectional study in neonates admitted to neonatal intensive care unit (NICU). Setting for the research was Dept. of Transfusion Medicine and Neonatology division of Sree Avittom Thirunal Hospital for women and children attached to Govt. Medical College, Trivandrum.

\section{MATERIALS AND METHODS}

Demographic details and maternal details were recorded. Cause for hyperbilirubinaemia was noted down and it was classified by AAP chart. Maternal antibody-mediated hyperbilirubinaemia was diagnosed according to inclusion criteria.

\section{RESULTS}

2619 neonates were admitted in NICU. 340 infants were admitted for treatment of hyperbilirubinaemia. Among them, 158 (6\%) had hyperbilirubinaemia due to HDFN and 182 (7\%) had hyperbilirubinaemia due to other causes. The rest 2279 (87\%) had other ailments. Five categories of red cell antibodies were found in HDFN. Anti-A (58.2\%), anti-B (11.4\%), anti-D (27.8\%), anti-c (1.3\%) and anti-E (1.3\%). All mothers of infants with ABO-HDFN were having O blood group. No antibodies outside ABO or Rh blood group systems were detected.

Statistical Analysis- All statistical data were analysed using SPSS software version 16.

\section{CONCLUSION}

HDFN is an important cause for hyperbilirubinaemia in neonates. ABO haemolytic disease was commoner and Group A or B neonates born to 0 Group mothers were at risk for HDFN. Rh HDFN due to anti-D is common than other clinically significant Rh antibodies.

\section{KEYWORDS}

Haemolytic Disease of Foetus and Newborn, Hyperbilirubinaemia, Antibody, ABO/Rh Blood Group System.

HOW TO CITE THIS ARTICLE: Vilambil S, Dharmadas M, Usha KKC, et al. Frequency of antibodies in haemolytic disease of foetus and newborn. J. Evolution Med. Dent. Sci. 2017;6(66):4751-4756, DOI: 10.14260/Jemds/2017/1029

\section{BACKGROUND}

Haemolytic disease of foetus and newborn (HDFN), portrayed as 'foetus carnosus' by Hippocrates, had always scripted its exigent presence in the frontiers of transfusion immunology. ${ }^{1}$ Triggered by enhanced destruction of red blood cells, HDFN could be associated with immune-mediated destruction,

Financial or Other, Competing Interest: None.

Submission 08-07-2017, Peer Review 07-08-2017,

Acceptance 12-08-2017, Published 17-08-2017.

Corresponding Author:

Dr. Sajith Vilambil,

Assistant Professor,

Department of Transfusion Medicine,

Government Medical College,

Thrissur- 680596, Kerala.

E-mail: drsajithmenon@gmail.com

DOI: $10.14260 /$ jemds $/ 2017 / 1029$ intrinsic abnormalities such as haemoglobinopathies, erythrocyte enzyme defects and membrane irregularities and acquired aberrations related to infections. ${ }^{2}$ Immune mediated HDFN is an ailment in which lifespan of infant's erythrocytes are shortened by the action of placentally transferred maternal antibodies specific for inherited paternal red cell antigens. ${ }^{3}$ Aim of this study was to identify the frequency of maternal antibodies in neonates with hyperbilirubinaemia in a tertiary care centre.

\section{MATERIALS AND METHODS}

This was a cross-sectional study conducted in 2619 neonates who were admitted to neonatal intensive care unit (NICU). Setting for the research was Dept. of Transfusion Medicine and Neonatology division of Sree Avittom Thirunal Hospital for women and children attached to Govt. Medical College, Trivandrum. 
According to institutional policy, all neonates with hyperbilirubinaemia and those born to mothers with antenatal antibody screen positivity were admitted in newborn nursery. As per the protocols, complete work-up was done for each infant with hyperbilirubinaemia in newborn nursery.

Demographic details such as name, age, IP no., bed no. and addresses were noted. Maternal details such as age and blood group were recorded. If there was hyperbilirubinaemia, the cause for the same was noted down. For classifying hyperbilirubinaemia, chart provided by American Academy of Paediatricians (AAP) was followed (Figure 1).

\section{Inclusion Criteria for ABO-HDFN}

1. Hyperbilirubinaemia within first 24 hours of birth.

2. ABO incompatibility between mother and baby.

3. Same Rh-D type as that of mother.

4. Maternal antibody screen negative for other blood group systems.

5. Maternal IgG titre of anti-A or anti-B $\geq 32$.

6. Neonatal DAT and elution positive/ elution alone positive/ IAT positive for maternal antibodies in cord blood serum.

7. No other diagnosed aetiology for hyperbilirubinaemia.

\section{Inclusion Criteria for Other HDFN}

1. Maternal antibody screen positive and presence of corresponding antigen in the neonate.

2. No ABO incompatibility between mother and neonate.

3. Positive DAT and elution in neonate.

4. Hyperbilirubinaemia within first 24 hours of birth.

\section{Exclusion Criteria}

HDFN along with twin-to-twin transfusion, high output cardiac failure, congenital infection or sepsis, hereditary spherocytosis, glucose-6-phosphate dehydrogenase deficiency, pyruvate kinase deficiency, $\alpha$-Thalassemia, extravascular blood loss, cephalhematoma, hypothyroidism, Dubin-Johnson syndrome, cystic fibrosis, biliary atresia, cholestasis, total parenteral nutrition and antibiotic therapy. Neonates having ABO incompatibility along with other minor blood group incompatibility.

Further investigations such as neonatal blood group, haemoglobin and bilirubin levels were recorded. Duration of treatment and ICU stay were noted.

\section{Ethics}

Study was approved by Human Ethical Committee and review board of institution. Study was accomplished for a period of 18 months from 01-03-2012 to 30-08-2013. Parents of all study subjects were counselled separately about the nature and effects of the study and a written consent was obtained from them.

\section{Statistical Analysis}

All statistical data were analysed using SPSS software version 16. Continuous variables were expressed as mean \pm standard deviation and qualitative data was expressed as frequencies and percentages. Independent samples t-test (Independent t- test or student ' $\mathrm{t}$ ' test) was used for comparing quantitative data between groups. All ' $p$ ' values were two tailed and values of $p<0.05$ were considered statistically significant.

\section{RESULTS}

\begin{tabular}{|c|c|c|}
\hline Admission Details & Frequency & Percentage \\
\hline Hyperbilirubinaemia due to HDFN & 158 & 6 \\
\hline $\begin{array}{c}\text { Hyperbilirubinaemia due to other } \\
\text { causes }\end{array}$ & 182 & 7 \\
\hline Other diseases & 2279 & 87 \\
\hline Total neonatal admissions & 2619 & 100 \\
\hline
\end{tabular}

Table 1. Admissions in Neonatal Intensive Care Unit

2619 neonates were admitted in neonatal intensive care unit during the study period; 340 infants were admitted for treatment of hyperbilirubinaemia. Among infants admitted in NICU, $158(6 \%)$ had hyperbilirubinaemia due to HDFN and $182(7 \%)$ had hyperbilirubinaemia due to other causes. The rest $2279(87 \%)$ cases were admitted for treatment of other ailments.

Five categories of red cell antibodies were found in neonates affected with HDFN. They were anti-A, anti-B, anti$\mathrm{D}$, anti-c and anti-E. Their frequencies are shown in Table 2.

\begin{tabular}{|c|c|c|}
\hline Antibody & Frequency & Percentage \\
\hline Anti-A & 92 & 58.2 \\
\hline Anti-B & 18 & 11.4 \\
\hline Anti-D & 44 & 27.8 \\
\hline Anti-c & 2 & 1.3 \\
\hline Anti-E & 2 & 1.3 \\
\hline Total & 158 & 100.0 \\
\hline
\end{tabular}

Among the mothers of infants with HDFN 36 (22.8\%) belonged to $18-22$ years, 72 (45.6\%) belonged to $23-27$ years, $32(20.2 \%)$ belonged to 28 - 32 years, $17(10.8 \%)$ belonged to $33-37$ years and $1(0.6 \%)$ belonged to $38-42$ years. While analysed the parity of mothers, $72(45.6 \%)$ belonged to primi gravida, $60(38 \%)$ to second gravida, 18 $(11.4 \%)$ to third gravida and $8(5 \%)$ to fourth gravida. There were $90(57 \%)$ of vaginal delivery, $32(20.3 \%)$ of induced vaginal delivery and $36(22.7 \%)$ of caesarean section among mothers; 84 (53.2\%) belonged to male gender and 74 (46.8\%) to female gender. Among infants with HDFN, 126 (79.7\%) had birth weight of $2500 \mathrm{~g}$ or more and $32(20.3 \%)$ had less than $2500 \mathrm{~g} ; 149$ (94.3\%) were term babies and 9 (5.7\%) were preterm babies; 144 (91.1\%) infants had APGAR score 7 - 10 and 14 (8.9\%) were with APGAR score 4 - 6.

All mothers of infants with ABO-HDFN were having 0 blood group. No antibodies outside $\mathrm{ABO}$ or Rh blood group systems were detected. So, the cases were categorised into two groups; those having ABO-HDFN and Rh-D HDFN. Mean of five variables; maternal age, cord blood bilirubin levels, cord blood haemoglobin values, treatment duration and duration of stay in ICU were compared.

In ABO-HDFN, mean maternal age was $25.74 \pm 4.76$ and in Rh-D HDFN it was $27 \pm 5.06$. The minimum age of mothers in both groups was 18 years and maximum age was 37 and 39 years in $A B O$ and $\mathrm{Rh}-\mathrm{D}$ respectively. Mean values of age of mothers of neonates with $\mathrm{ABO}$ and Rh-D HDFN were compared using independent ' $\mathrm{t}$ ' test. No significant difference was observed with a 'p' value of 0.1462 . 
The mean cord blood bilirubin levels in ABO and Rh-D HDFN infants were $5.157 \pm 1.906$ and $4.148 \pm 1.104$ respectively. Minimum bilirubin levels in $\mathrm{ABO}$ and Rh-D HDFN were 3 and $1.8 \mathrm{mg} \%$. Maximum bilirubin levels in ABO and Rh-D HDFN were 10.6 and $8.8 \mathrm{mg} \%$ respectively. Mean values of cord blood bilirubin in neonates with $\mathrm{ABO}$ and Rh-D HDFN were compared using independent ' $\mathrm{t}$ ' test. Significant difference was observed with a ' $p$ ' value of $0.0012 ; 95 \%$ confidence interval was 0.404 to 1.615 and ' $t$ ' value was 3.2949.

The mean cord blood haemoglobin values in ABO and RhD HDFN infants were $17.096 \pm 2.659$ and $14.470 \pm 1.975$ respectively. Minimum haemoglobin values in ABO and Rh-D HDFN were 11.1 and $9.8 \mathrm{~g} \%$. Maximum haemoglobin values in $\mathrm{ABO}$ and Rh-D HDFN were 22.6 and $17.7 \mathrm{~g} \%$ respectively. Mean values of umbilical cord haemoglobin in neonates with ABO and Rh-D HDFN were compared using independent ' $\mathrm{t}$ ' test. Significant difference was observed with a ' $p$ ' value of $0.0001 ; 95 \%$ confidence interval was 1.750 to 3.501 and ' $t$ ' value was 5.9259 .

Mean treatment duration in infants with $\mathrm{ABO}$ and Rh-D HDFN were $3.13 \pm 3.32$ and $2.91 \pm 2.94$ days respectively. Median treatment duration was 3 and 3.5 days and maximum treatment duration was 10 and 9 days in $\mathrm{ABO}$ and Rh-D HDFN respectively. Mean values of duration of treatment of neonates with $\mathrm{ABO}$ and Rh-D HDFN were compared using independent ' $t$ ' test. No significant difference was observed with a 'p' value of 0.7044 .

Mean duration of stay of infants with $\mathrm{ABO}$ and Rh-D HDFN in ICU were $7.21 \pm 2.96$ and $6.84 \pm 2.73$ days respectively. All neonates were observed in ICU for a minimum of 5 days and a maximum of 14 and 15 days for $\mathrm{ABO}$ and Rh-D HDFN. Mean values of duration of stay of neonates with ABO and Rh-D HDFN in ICU were compared using independent ' $\mathrm{t}$ ' test. No significant difference was observed with a 'p' value of 0.4770 .

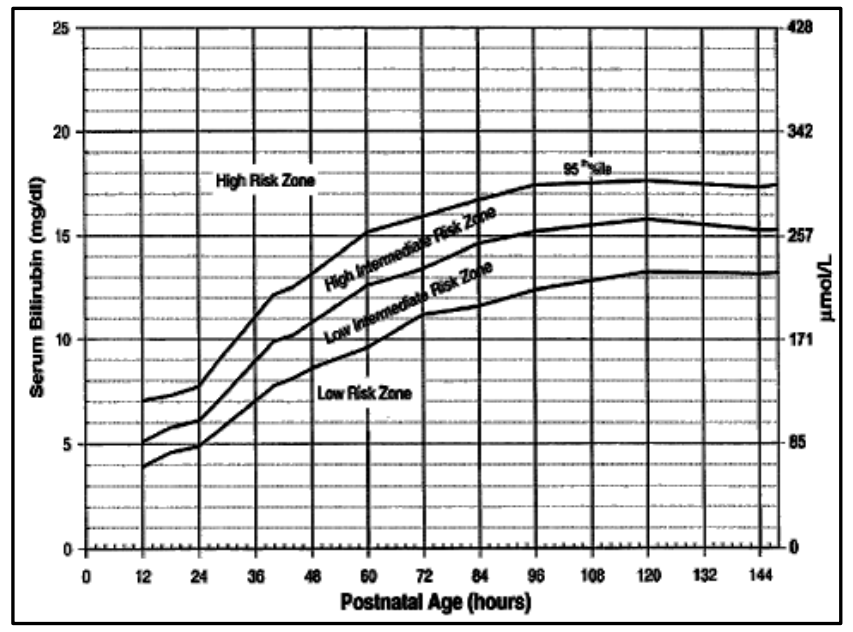

Figure 1. AAP Chart for Assessing Risk of Hyperbilirubinaemia

\section{DISCUSSION}

In early 1500s, five babies of Katherine of Aragon, the first wife of Henry VIII, were either stillborn or deceased in early newborn period due to HDFN. ${ }^{4}$ Haemolytic disease was first described in 1609 by a French midwife in a set of twins, one of whom was hydropic and stillborn, while the other one was severely jaundiced and died of kernicterus. ${ }^{5}$ In 1641, Plater contributed a definitive description of hydrops foetalis. ${ }^{4}$ The mystery behind many clinically observed scenarios of HDFN involving red cell haemolysis, ranging widely from severely hydropic stillborn foetuses to infants with mild or significant levels of jaundice and kernicterus were not realised completely until twentieth century. ${ }^{6}$

In 1892, Ballantyne described a criteria for diagnosing HDFN in 1912, Diamond, Blackfan and Baty investigated the associated clinical features and in 1938 Hellman and Hertig first recognised the familial incidence of disease. ${ }^{4}$ In 1938 Dr. Ruth of Women and Children Hospital, Chicago, who was a sufferer of Rh haemolytic disease, investigated and published a comprehensive analysis on Icterus Gravis Neonatorum. ${ }^{7}$ In 1939, Philip Levine and Stetson reported a case of HDFN where the mother was sensitised by paternal antigens present on foetal red cells. ${ }^{8}$ Darrow observed that the mother was an unaffected constant factor, first child was seldom afflicted and the disease resulted from an acquired immune reaction. ${ }^{9}$

In 1940, Dr. Karl Landsteiner and Dr. Alexander Weiner detected $\mathrm{Rh}$ factor by their experiments. ${ }^{10}$ In 1946, Diamond et al developed a method of exchange transfusion for affected infants. ${ }^{11}$ In 1956, it was proved that the analysis of bilirubin content in amniotic fluid was a good indicator of severity and morbidity of disease. ${ }^{4}$ First intrauterine transfusion was performed in 1963.11 Weiner and Peters opined that the transfusion of $\mathrm{Rh}$ positive blood to $\mathrm{Rh}$ negative individuals could result in development of anti-Rh agglutinins. ${ }^{12}$

This was a research conducted in the Dept. of Transfusion Medicine and Neonatology division in the Dept. of Paediatrics, Govt. Medical College, Thiruvananthapuram. All neonates admitted in newborn nursery with hyperbilirubinaemia were screened for HDFN according to the inclusion criteria.

In our study, total admissions in newborn nursery during the study period were 2619, out of which 340 (13\%) neonates had hyperbilirubinaemia. Among 340 hyperbilirubinaemia neonates, 158 (6\% of total) fulfilled the criteria of HDFN. This constituted $46.47 \%$ of jaundiced babies. Five types of antibodies were found to be associated with HDFN, which included anti-A, anti-B, anti-D, anti-c and anti-E. Weinstein opined that $98 \%$ of HDFN was due to ABO and $\mathrm{Rh}$ incompatibilities, whereas the rest $2 \%$ was due to antibodies against other blood group antigens. ${ }^{13}$

A 12-year study conducted in Sweden comprising of 110,765 pregnant women found out 836 alloantibodies and its percentages were: D-9.0\%, E-6.1\%, C- $4.3 \%$, Cw- $1.2 \%$, c4.5\%, e- $0.1 \%$, Kell-5.7\%, Duffy-3.1\%, MNSs-4.2\%, Kidd-1.2\%, Lutheran-1.6\%, P1-5.7\%, Lewis-28.8\%, Others-14.4\%.14 A prospective South Indian study carried out in 624 antenatal women gave a positive antibody screen in 9 cases (1.44\%); anti-D-6 (0.96\%), anti-D with anti-c-2 (0.32\%) and anti-M-1 $(0.16 \%) .{ }^{15}$ A study conducted in same setting among $2469 \mathrm{D}$ negative females showed a D-alloimmunisation of $3.12 \%$ and frequency of Rh-D HDFN was $2.28 \% .{ }^{16}$

Singhvi Arpita et al studied distribution of neonatal jaundice due to blood group incompatibility. The distribution of $\mathrm{ABO}$ and $\mathrm{Rh}$ incompatibility was equal. But in this research, the frequency of ABO-HDFN was more than twice that of $\mathrm{Rh}$ HDFN. They opined that blood group incompatibility is an important cause of neonatal jaundice. ${ }^{17}$ 
Mohammad Irshad et al studied prevalence of $\mathrm{Rh}$ and ABO incompatibility in jaundiced neonates. Out of 200 neonates, $70 \%$ were male and $30 \%$ were female. But in our research, it was varying, $53.2 \%$ belonged to male gender and $46.8 \%$ belonged to female gender. In their study, frequency of ABO incompatibility and Rh-incompatibility in jaundiced neonates was $22.5 \%$ and $12.5 \%$ respectively. In our research, it was $32.4 \%$ and $14 \%$ respectively. They found out that out of the remaining $65.5 \%$ cases physiological jaundice was diagnosed in $40.5 \%$ neonates, prematurity in $15 \%$ neonates and G6PD in $9.5 \%$ neonates. Among those $22.5 \%$ cases of $\mathrm{ABO}$ incompatibility in their study, there were $16.5 \%$ males and $6 \%$ females. Majority $15 \%$ presented on 1st day of life followed by $3 \%$ on $2^{\text {nd }}$ and 3 rd day of life respectively, $1 \%$ on 4 th day and $0.5 \%$ on 5 th day of life. ${ }^{18}$

Association of $\mathrm{ABO}$ and $\mathrm{Rh}$ incompatibility with neonatal hyperbilirubinaemia was researched by Apexa S Patel et al. The incidence of $\mathrm{ABO}$ incompatibility was $13.79 \%$ and of $\mathrm{Rh}$ incompatibility was $1.37 \%$. In ABO incompatibility group, $90 \%$ newborn developed clinical jaundice. In treated group, out of 88 newborns, 82 were from 0 -A and O-B incompatibility group. ${ }^{19}$

A study by Ashutosh Kumar et al similarly showed that $\mathrm{ABO}$ incompatibility was the leading cause of haemolysis (in $48 \%$ ) followed by $\mathrm{Rh}$ incompatibility (in $22 \%$ ), septicaemia in $26 \%$ and G6PD deficiency in $4 \% .^{20}$

Out of 158 cases of HDFN, 110 occurred due to antibodies against antigens in ABO blood group system. In ABO-HDFN, 92 (58.2\% of total) cases were due to anti-A and 18 (11.4\% of total) cases were due to anti-B. Dinesh et al observed that ABO incompatibility was the leading cause of HDFN in countries with high human development index and similar results were obtained in this study. ${ }^{21}$ All mothers of infants with ABO-HDFN were invariably Group O. This observation made it clear that in Group 0 serum, IgG was the major isotype for anti-A and anti-B. Rawson opined that since IgG anti-A and anti-B occurred more commonly in Group 0 than in Group B and A mothers, ABO-HDFN almost invariably belonged to infants of Group 0 mothers. ${ }^{22}$ Hence, HDFN was more common among neonates of Group $\mathrm{O}$ mothers. Rosenfield et al, Rawson et al and Kochwa et al obtained similar results. ${ }^{22,23,24}$ Similarly, in India Gupte and Bhatia observed that ABO-HDFN was more seen with Group A or B neonates born to Group 0 mothers. But in one series of 45 cases by Munk Anderson, the mother was Group 0 in 43 instances and subgroup $A_{2}$ in the remaining two and $A_{2}$ mothers produced much stronger and incomplete anti-B than $\mathrm{A}_{1}$ mothers. ${ }^{25}$

In our analysis within $0-\mathrm{A}$ and $\mathrm{O}-\mathrm{B}$ incompatibilities, $\mathrm{O}-\mathrm{A}$ occurred at a higher frequency. The ratio being $5.1: 1$. Fischer et al had reviewed that this ratio came around $2.7-3.7: 1 .{ }^{26} \mathrm{~A}$ slightly higher ratio in our study might be due to the strong antigenic expression of A-antigen in Asian population, which was in turn determined by racial and environmental factors. As observed by Romano et al, the higher incidence of ABOHDFN in many populations was due to rise in anti-A titres associated with ascaris infestation. ${ }^{27}$ In a research by Chan Shu and Blair, there was no difference between Group A and Group B infants in the frequency and severity of haemolytic process. $^{28}$

During our study period 110 ABO-HDFN cases occurred among 9,978 deliveries, the frequency being $1.1 \%$. Voak et al had performed a research for detection of immune anti-A/B and prediction of ABO-HDFN in a screen series on 5,704 sera from Group 0 mothers. Frequency of ABO-HDFN was $0.8 \%$ in that study. ${ }^{29}$ Murray et al observed that the frequency of HDFN triggered by anti-A was about 1 in 150 births and even lesser for anti-B. 30

The relative frequency of ABO-HDFN varied in different populations. ${ }^{31}$ In Venezuela, $16 \%$ of neonates exhibited foetomaternal $\mathrm{ABO}$ incompatibility and the incidence of $\mathrm{ABO}$ HDFN was $5 \%{ }^{32} \mathrm{ABO}$-HDFN was more frequent and severe in Arab population. ${ }^{33}$ Incidence of ABO-HDFN was found to be substantially higher in Central America and lesser in South and North America. ${ }^{34}$ With respect to ethnic groups, the prevalence of maternal-newborn $\mathrm{ABO}$ incompatibility ranged from $31 \%$ in Europeans to $50 \%$ in Asians. 35 Bhatia had reported the incidence of ABO-HDFN in India as 1 in 200 in serologically diagnosed and 1 in 650 in haematologically diagnosed cases.

According to Schonitzer et al, the ABO-HDFN had a worldwide incidence of 54.4 per 1,000 births. ${ }^{36}$ They also opined that frequency of ABO-HDFN necessitating therapy was approximately $5 \%$ of all neonatal hyperbilirubinaemias. ${ }^{37}$ Levine and Meyer opined that confusion existed regarding the true incidence of ABO-HDFN, because of the ambiguity in the significance of various laboratory investigations commonly employed for its evaluation. ${ }^{38}$ This could be the reason for disparity of results in previous studies and our study.

Among 48 Rh HDFN cases (30.4\% of total) anti-D was the commonest, which affected 44 neonates $(27.8 \%$ of total). Other two antibodies were anti-c and anti-E, each of which was found in $1.3 \%$ of neonates. According to Astrup and Kornstad frequency of haemolytic disease due to anti-c was small, because anti-c titre was often low in maternal sera and c antigen was often negative in neonatal red cells. ${ }^{39,40}$ The frequency of Rh-D negative women in India ranged from $6 \%$ to $8 \%$ in different studies. ${ }^{35}$ Prevalence of Rh-D alloimmunisation from different centres had a wide range from $0.8 \%$ to $4.0 \%$ and one study conducted in the same setting reported a frequency of $3.12 \% .41,42,43,44$

While independent ' $t$ ' test was performed between $\mathrm{ABO}$ and Rh-D HDFN assemblies there was no significant difference regarding maternal age, duration of treatment and duration of stay in ICU. Regarding cord blood haemoglobin and bilirubin levels, there was significant difference in mean values in ABO and Rh-D HDFN cases.

The research was designed as a cross-sectional descriptive study and hence there were some limitations in assessing the risk between variables with a limited data. For procuring more information concerning this disease, it is suggested to undertake long-term analytical studies with greater numbers of samples and using controls to assess correlation between several parameters related to incidence of HDFN.

\section{CONCLUSION}

1. HDFN is an important cause for Hyperbilirubinaemia in neonates.

2. ABO haemolytic disease was found to be more common than Rh haemolytic disease. 
3. Group A or B neonates born to O Group mothers were at increased risk for ABO-HDFN.

4. Rh HDFN due to anti-D is common than other clinically significant $\mathrm{Rh}$ antibodies.

5. Regarding maternal age, treatment duration, duration of stay in ICU there was no significant difference in mean values in ABO and Rh-D HDFN cases.

6. Regarding cord blood haemoglobin and bilirubin levels, there was significant difference in mean values in $A B O$ and Rh-D HDFN cases.

\section{ACKNOWLEDGEMENT}

We acknowledge Dr. Anupa Lucas, Dr. Rajany Jose and Dr. Reshmi Ramachandran, Assistant Professors in Dept. of Community Medicine, Govt. Medical College, Thrissur, for their unwavering support and perpetual inspiration in this research. We offer our sincerest obligation to Dr. Lalitha Kailas, Professor and HOD in Dept. of Paediatrics, Gokulam Medical College, Trivandrum, and Dr. Shobha Kumar, Professor in Dept. of Paediatrics, Govt. Medical College, Trivandrum, for their scholarly guidance in the course of this work.

\section{REFERENCES}

[1] Santavy J. Hemolytic disease in the newborn-history and prevention in the world and the Czech Republic. Biomed Pap Med Fac Univ Palacky Olomouc Czech Repub 2010;154(2):147-51.

[2] Klein H, Anstee D. Mollison's blood transfusion in clinical medicine. $11^{\text {th }}$ edn. Blackwell Publishing Ltd 2005:P 496.

[3] Kennedy MS. Perinatal issues in transfusion practice. 17th edn. AABB technical manual, AABB press 2011:P 631.

[4] Sowers HM. Hemolytic disease of the newborn. California association for medical laboratory technology. CAMLT distance learning course. DL-995.

[5] Bowman JM. RhD hemolytic disease of the newborn. N Engl J Med 1998;339(24):1775-7.

[6] Diamond LK, Blackfan KD, Baty JM. Erythroblastosis fetalis and its association with universal edema of the fetus, icterus gravis neonatorum and anemia of the newborn. J Pediatr 1932;1(3):269-309.

[7] Zimmerman DR. Appendix, research on the fetus. Rh. New York: MacMillan Publishing Co. Inc 1973.

[8] Levine P, Stetson RE. An unusual case of intra-group agglutination. J Am Med Assoc 1939;113(2):126-7.

[9] Darrow RR. Icterus gravis (erythroblastosis) neonatorum. Arch Pathos 1938;25:3-37.

[10] Landsteiner K, Weiner AS. An agglutinable factor in human blood recognized by immune sera in Rhesus blood. Soc Exp Biol New York 1940;42(1):223.

[11] Goldstein P. Birth asphyxia. In: Smith GF, Vidyasagar D, (eds). Historical review and recent advances in neonatal and perinatal medicine. Mead Johnson Nutritional Division 1980.

[12] Weiner AS, Peters HR. Hemolytic reactions following transfusions of blood of the homologous group, with three cases in which the same agglutinogen was responsible. Am Int Med 1940:43-60.
[13] Weinstein L. Irregular antibodies causing haemolytic disease of the newborn: a continuing problem. Clin Obstet Gynaecol 1982;25(2):321-32.

[14] Filbey D, Hanson U, Wesström G. The prevalence of red cell antibodies in pregnancy correlated to the outcome of the newborn: a 12 year study in central Sweden. Acta Obstet Gynecol Scand 1995;74(9):68792.

[15] Devi SAM, Alwar VA, Sitalakshmi S, et al. Red blood cell antibody screening in pregnancy. AJTS 2011;5(1):56.

[16] Shaiji PS. Clinical profile and outcome of Rh-D alloimmunized pregnancies in a tertiary care centre, MD thesis 2011.

[17] Arpita S, Gajendra GN, Rekha N. A study of distribution of neonatal jaundice due to blood group incompatibility. Journal of Science 2016;6(2):94-9.

[18] Irshad M, Mohammad A, Hussain M, et al. Prevalence of rhesus type and abo incompatibility in jaundiced neonates. JPMI 2011;25(3):233-9.

[19] Patel AS, Desai DA, Patel AR. Association of ABO and $\mathrm{Rh}$ incompatibility with neonatal hyperbilirubinaemia. International Journal of Reproduction, Contraception, Obstetrics and Gynecology 2017;6(4):1368-75.

[20] Kumar A, Patel MK, Chavda B, et al. Hemolytic disease of the newborn: a study of 50 cases. International Journal of Scientific Study 2013;1(3):95-9.

[21] Dinesh D. Review of positive direct antiglobulin tests found on cord blood sampling. J Paediatric Child Health 2005;41(9-10):504-7.

[22] Rawson AJ, Abelson NM. Studies of blood group antibodies. IV. Physicochemical differences between isoanti-A,B and isoanti-A or isoanti-B. J Immunol 1960;85:640-7.

[23] Rosenfield RE. A-B hemolytic disease of the newborn. Analysis of 1480 cord blood specimens, with special reference to the direct antiglobulin test and to the group 0 mother. Blood 1955;10:17.

[24] Kochwa S, Rosenfield RE, Tallal L, et al. Isoagglutinins associated with ABO erythroblastosis. J Clin Invest 1961;40(5):874-83.

[25] Munk-Andersen G. Excess of group 0-mothers in ABOhaemolytic disease. Acta Pathol Microbiol Scand 1958;42(1):43-80.

[26] Fischer K. Morbus haemolyticus neonatorum im ABOsystem. Stuttgart: Georg Thieme Verlag 1961.

[27] Romano EL, Rossi DML, Hagel I, et al. Infestacion por ascaris: una posible explicacion para los altos niveles de IgG anti-A observados en la poblacion venezolana. Acta Cient Venezol 1988;39(1):75-8.

[28] Chan-Shu SY, Blair O. ABO hemolytic disease of the newborn. Am J Clin Pathol 1979;71(6):677-9.

[29] Voak D, Bowley CC. A detailed serological study on the prediction and diagnosis of $\mathrm{ABO}$ haemolytic disease of the newborn (ABO HD). Vox Sanguinis 1969;17(5):321-48.

[30] Murray NA, Roberts IAG. Haemolytic disease of the newborn. Arch Dis Child Fetal Neonatal Ed 2007;92(2):F83-8. 
[31] Peevy KJ, Wiseman HJ. ABO hemolytic disease of the newborn: evaluation of management and identification of racial and antigenic factors. Pediatrics 1978;61(3):475-8.

[32] Klein H, Anstee D. Mollison's blood transfusion in clinical medicine. $11^{\text {th }}$ edn. Blackwell Publishing Ltd 2005:P 530.

[33] Al-Jawad ST, Keenan P, Kholeif S. Incidence of ABO haemolytic disease in a mixed Arab population. Saudi Med J 1985;7:41-5.

[34] Huntley CC, Lyerley AD, Littlejohn MP, et al. ABO hemolytic disease in Puerto Rico and North Carolina. Pediatrics 1976;57(6):875-83.

[35] Solheim BG, Grönn M. Hemolytic disease of the fetus and newborn. $4^{\text {th }}$ edn. Rossi's principles of transfusion medicine. Blackwell Publishing Ltd 2009:P 420.

[36] Dufour DR, Monoghan WP. ABO hemolytic disease of the newborn. A retrospective analysis of 254 cases. Am J Clin Pathol 1980;73(3):369-73.

[37] Schönitzer D, Frisch H. Incidence, laboratory diagnosis and serologic prediction of hemolytic disease of newborn infants due to ABO incompatibility. Padiatr Padol 1984;19(3):263-78.
[38] Levine DH, Meyer HB. Newborn screening for ABO hemolytic disease. Clin Pediatr (Phila) 1985;24(7):391-4.

[39] Astrup J, Kornstad L. Presence of anti-c in the serum of 42 women giving birth to $c$ positive babies: serological and clinical findings. Acta Obstet Gynecol Scand 1977;56(3):185-8.

[40] Bowell PJ, Brown SE, Dike AE, et al. The significance of anti-c alloimmunization in pregnancy. Br J Obstet Gynaecol 1986;93(10):1044-8.

[41] MacKenzie IZ, Bowell P, Gregory H, et al. Routine antenatal rhesus D immunoglobulin prophylaxis: the results of a prospective 10 year study. British Journal of Obstetrics and Gynaecology 1999;106(5):492-7.

[42] Furundarena JR, Ibisate A, Burguete Y, et al. Rh (D) alloimmunization and pregnancy. Analysis of the causes after prophylaxis introduction. Sangre (Barc) 1999;44(6):429-33.

[43] Suzanne B, Françoise NS. High prevalence of anti-D antibodies among women of childbearing age at centre pasteur of cameroon. Afr J Reprod Health 2009;13(3):47-52.

[44] Rao RR, Gupte SC, Dastur NA, et al. A review of 58 Rhisoimmunised cases. Asia-Oceania Journal of Obstetrics and Gynaecology 1986;12(2):207-11. 